Cochrane Database of Systematic Reviews

\title{
Adhesives for fixed orthodontic bands (Review)
}

Millett DT, Glenny AM, Mattick RCR, Hickman J, Mandall NA

Millett DT, Glenny AM, Mattick RCR, Hickman J, Mandall NA.

Adhesives for fixed orthodontic bands.

Cochrane Database of Systematic Reviews 2016, Issue 10. Art. No.: CD004485.

DOI: 10.1002/14651858.CD004485.pub4.

www.cochranelibrary.com 
HEADER

ABSTRACT

PLAIN LANGUAGE SUMMARY

BACKGROUND

OBJECTIVES

METHODS

RESULTS

DISCUSSION

AUTHORS' CONCLUSIONS

ACKNOWLEDGEMENTS

REFERENCES

CHARACTERISTICS OF STUDIES

ADDITIONAL TABLES

APPENDICES

WHAT'S NEW

HISTORY

CONTRIBUTIONS OF AUTHORS

DECLARATIONS OF INTEREST

SOURCES OF SUPPORT

NOTES

INDEX TERMS

\section{TABLE OF CONTENTS}

1

1

2

3

3

4

5

7

8

8

9

11

15

16

17

18

18

18

18

19

19 
[Intervention Review]

\section{Adhesives for fixed orthodontic bands}

Declan T Millett ${ }^{1}$, Anne-Marie Glenny² ${ }^{2}$ Rye CR Mattick ${ }^{3}$, Joy Hickman4, Nicky A Mandall 5

1Oral Health and Development, Cork University Dental School and Hospital, Cork, Ireland. 2Division of Dentistry, School of Medical Sciences, Faculty of Biology, Medicine and Health, The University of Manchester, Manchester, UK. ${ }^{3}$ Department of Orthodontics, Newcastle Dental Hospital, Newcastle upon Tyne, UK. ${ }^{4}$ Department of Orthodontics, Glan Clwyd Hospital, Rhyl, UK. ${ }^{5}$ Orthodontic Department, Tameside General Hospital, Ashton under Lyne, UK

Contact address: Declan T Millett, Oral Health and Development, Cork University Dental School and Hospital, University College, Cork, Ireland.d.millett@ucc.ie.

Editorial group: Cochrane Oral Health Group.

Publication status and date: Stable (no update expected for reasons given in 'What's new'), published in Issue 11, 2016.

Citation: Millett DT, Glenny AM, Mattick RCR, Hickman J, Mandall NA. Adhesives for fixed orthodontic bands. Cochrane Database of Systematic Reviews 2016, Issue 10. Art. No.: CD004485. DOI: 10.1002/14651858.CD004485.pub4.

Copyright @ 2016 The Cochrane Collaboration. Published by John Wiley \& Sons, Ltd.

\section{A B S T R A C T}

\section{Background}

Orthodontic treatment involves using fixed or removable appliances (dental braces) to correct the positions of teeth. It has been shown that the quality of treatment result obtained with fixed appliances is much better than with removable appliances. Fixed appliances are, therefore, favoured by most orthodontists for treatment. The success of a fixed orthodontic appliance depends on the metal attachments (brackets and bands) being attached securely to the teeth so that they do not become loose during treatment. Brackets are usually attached to the front and side teeth, whereas bands (metal rings that go round the teeth) are more commonly used on the back teeth (molars). A number of adhesives are available to attach bands to teeth and it is important to understand which group of adhesives bond most reliably, as well as reducing or preventing dental decay during the treatment period.

\section{Objectives}

To evaluate the effectiveness of the adhesives used to attach bands to teeth during fixed appliance treatment, in terms of:

(1) how often the bands come off during treatment; and

(2) whether they protect the banded teeth against decay during fixed appliance treatment.

\section{Search methods}

The following electronic databases were searched: Cochrane Oral Health's Trials Register (searched 2 June 2016), Cochrane Central Register of Controlled Trials (CENTRAL; 2016, Issue 5) in the Cochrane Library (searched 2 June 2016), MEDLINE Ovid (1946 to 2 June 2016) and EMBASE Ovid (1980 to 2 June 2016). We searched ClinicalTrials.gov and the World Health Organization International Clinical Trials Registry Platform for ongoing trials. No restrictions were placed on the language or date of publication when searching the electronic databases.

\section{Selection criteria}

Randomised and controlled clinical trials (RCTs and CCTs) (including split-mouth studies) of adhesives used to attach orthodontic bands to molar teeth were selected. Patients with full arch fixed orthodontic appliance(s) who had bands attached to molars were included.

\section{Data collection and analysis}

All review authors were involved in study selection, validity assessment and data extraction without blinding to the authors, adhesives used or results obtained. All disagreements were resolved by discussion. 


\section{Main results}

Five RCTs and three CCTs were identified as meeting the review's inclusion criteria. All the included trials were of split-mouth design. Four trials compared chemically cured zinc phosphate and chemically cured glass ionomer; three trials compared chemically cured glass ionomer cement with light cured compomer; one trial compared chemically cured glass ionomer with a chemically cured glass phosphonate. Data analysis was often inappropriate within the studies meeting the inclusion criteria.

\section{Authors' conclusions}

There is insufficient high quality evidence with regard to the most effective adhesive for attaching orthodontic bands to molar teeth. Further RCTs are required.

\section{PLAIN LANGUAGE SUMMARY}

\section{Adhesives for fixed orthodontic bands}

There is insufficient evidence to determine the most effective adhesive for attaching orthodontic bands to molar teeth in patients with full arch fixed orthodontic appliances.

Orthodontic treatment involves using fixed or removable appliances (braces) on teeth to correct their position. It has been shown that the quality of treatment result obtained with fixed dental appliances is much better than with removable appliances. The success of a fixed dental appliance depends on the metal attachments (brackets and bands) being securely attached to the teeth so that they do not become loose during treatment. Brackets are usually attached to teeth other than molars, where bands (metal rings that go round the teeth) are more commonly used. There is insufficient evidence with regard to the most effective adhesive for attaching orthodontic bands to molar teeth. 


\section{B A C K G R O U N D}

Orthodontic treatment involves using fixed or removable appliances (dental braces) to correct the positions of teeth. In England and Wales between April 2001 and March 2002, claims for fixed appliances were made by the General Dental Services at an approximate cost of GBP 57 million to the National Health Service (DPB 2002).

In Finnish municipal health centres, the cost of orthodontic treatment per patient up to the age of 18 was, on average, FIM 7358, ranging from FIM 1299 to FIM 24,751 (Pietila 1998). In the US, orthodontic treatment accounted for $39 \%$ of the costs ( USD $2480+/$ - USD 364) of surgical-orthodontic treatment in community hospital care (Panula 2002).

\section{Who receives orthodontic treatment?}

The majority of orthodontic treatment is carried out for children aged 10 to 14 years and is primarily concerned with correcting severe crowding and rotations, buried teeth or very prominent teeth. In the UK, epidemiological data reveal that two thirds of 11 to 12 year old children have either a moderate or severe need for orthodontic treatment (Evans 1987; Holmes 1992). There is also a great demand for treatment with an average time on UK hospital waiting lists of 16 months (Russell 1999). Demand and need for orthodontics, however, is increasing among adults who now make up almost $25 \%$ of cases in US orthodontic practices (Keim 2002a).

\section{Adhesives for fixed orthodontic appliances}

It has been shown that the quality of treatment result obtained with fixed appliances is much better than with removable appliances (O'Brien 1993; Richmond 1993). Fixed appliances, are therefore, favoured by most orthodontists for treatment.

The success of a fixed appliance depends on the metal attachments (brackets and bands) being attached to the teeth so that they do not become detached during treatment. Brackets are usually attached to teeth other than molars, where bands (metal rings that go round each tooth) are more commonly used (Stirrups 1991). There should be a low rate of failure of brackets and bands. The need to replace bands, during a 2-year course of treatment, slows down the progress of treatment with a fixed appliance. It can also be costly in terms of clinical time, materials and time lost from education/work for the patient. Loose bands also predispose the tooth surface under the band to dental decay.

\section{Ideal properties of adhesive for banding fixed orthodontic appliances}

Orthodontic bands are subjected to a large number of forces in the mouth resulting in a complex distribution of stresses within the adhesive and its junctions with the enamel and the band interior (Durning 1994; Millett 1992).

Ideally the adhesive strength should be.

(1) Strong enough to keep the band on the tooth for the length of the treatment.

(2) Not so strong that the tooth surface is damaged when the band is removed.

The adhesive should ideally be.

(1) Easy to use clinically.
(2) Protective against dental caries (decay).

(3) Of reasonable cost.

Zinc phosphate, zinc silicophosphate and zinc polycarboxylate cements were used as principal band cements until the early 1990s (Gottlieb 1996). These cements are chemically-cured (Brown 1989; Øilo 1991). Zinc phosphate cements are usually supplied as a powder (which is principally zinc oxide) and a liquid, comprising an aqueous solution of phosphoric acid. Zinc silicophosphate cements are also supplied as powder and liquid; the powder is a mixture of zinc oxide and aluminosilicate glass and the liquid is an aqueous solution of phosphoric acid with buffers. Zinc polycarboxylate cements are supplied as either powder and acidic liquid or as powder which is mixed with water. For the former, the powder is finely ground zinc oxide which on occasion contains small quantities of other oxides, such as magnesium oxide. The liquid is an aqueous solution of about $40 \%$ polyacrylic acid. For the powder/water materials, the powder is zinc oxide and freezedried polyacrylic acid. The setting reaction of zinc polycarboxylate cements is by an acid-base reaction.

Some of these cements are still used by a small proportion of orthodontists for band cementation although most orthodontists now use a glass ionomer or glass ionomer based cement for this purpose (Keim 2002b). These newer cements may be classified as follows (McCabe 1998).

(1) Glass ionomer cements supplied as a powder with acidic liquid, or powder with water.

(2) Polyacid-modified composite resin (compomer) which are resin-matrix composites, similar to 'white' filling materials, and have some glass ionomer filler particles.

(3) Resin-modified glass ionomer cements which are hybrids of their resin-matrix and glass ionomer parent groups.

Glass ionomer cements set by an acid-base reaction (chemicalcuring) similar to that of zinc polycarboxylate cements whereas polyacid-modified composite resin (compomer) sets via free radicle polymerisation of the methacrylate groups, which is often light-activated (light-curing); there is no acid-base reaction. Resin-modified glass ionomers often have a tri-cure mechanism of setting: an acid-base reaction, a light-cured polymerisation reaction and a self cure polymerisation reaction.

With the number of adhesives available to apply bands to teeth, it is important to understand which group bonds most reliably, as well as reducing or preventing dental decay during the treatment period.

Null hypothesis:

There is no difference in the effectiveness of different types of adhesives in terms of how often the bands come off during treatment and whether they protect the banded teeth against decay during fixed orthodontic appliance treatment.

Working hypothesis:

Some types of orthodontic adhesives are better at bonding metal bands to teeth and protecting the teeth against decay during fixed orthodontic appliance treatment.

\section{O B JECT IVES}

To evaluate the effectiveness of the adhesives used to attach bands to teeth during fixed appliance treatment, in terms of: 
(1) how often the bands come off during treatment; and

(2) whether they protect the banded teeth against decay during fixed appliance treatment.

\section{METHODS}

\section{Criteria for considering studies for this review}

\section{Types of studies}

Randomised and controlled clinical trials, including those that use a split-mouth design, were included in this review.

\section{Types of participants}

Any patient with full arch fixed orthodontic appliance(s) who had bands attached to molars were included. Patients with cleft lip or palate were excluded due to the higher prevalence of molar crossbite in this group, which has been shown to significantly affect molar band failure rate and band survival time (Hodges 2001). Patients with other craniofacial syndromes were also excluded.

\section{Types of interventions}

Adhesives used to attach orthodontic bands to molar teeth. This excludes adhesives used to cement brackets (metal squares) to teeth which has been the subject of a separate review (Mandall 2003).

Studies which compare any of the six types of adhesive, zinc silicophosphate, zinc phosphate, zinc polycarboxylate, conventional glass ionomer, polyacid-modified composite resin (compomer), resin-modified glass ionomer with any other, were included.

Studies were excluded that:

(1) used headgear to molar bands;

(2) used intermaxillary elastic traction to molar bands;

(3) used soldered lingual or palatal arches to molar teeth;

(4) used bands cemented to primary molars or premolars or different molar types on opposite sides of the mouth; and

(5) followed patients for less than 6 months.

\section{Types of outcome measures}

Dichotomous data on the success of each adhesive (whether the metal band stays cemented to the tooth or not) were recorded. Where these data were not available, annualised failure rates of adhesives, i.e. the rate at which the metal bands become detached during treatment, were noted.

Dichotomous data on the presence or absence of decay (decalcification) associated with or around the bands were recorded. If data exist on size/area of decalcifications, these were also included.

\section{Search methods for identification of studies}

To identify studies for this review, we developed detailed search strategies for each database searched. These were based on the search strategy developed for MEDLINE (Ovid) but revised appropriately for each database. The search strategy used a combination of controlled vocabulary and free text terms and was linked with the Cochrane Highly Sensitive Search Strategy (CHSSS) for identifying randomised trials (RCTs) in MEDLINE: sensitivity maximising version (2008 revision) as referenced in Chapter
6.4.11.1 and detailed in box 6.4.c of the Cochrane Handbook for Systematic Reviews of Interventions Version 5.1.0 (updated March 2011) (Higgins 2011). Details of the MEDLINE search are provided in Appendix 3. The Embase subject search was linked to an adapted version of the Cochrane Embase Project filter for identifying RCTs in EMBASE via Ovid (see http://www.cochranelibrary.com/help/ central-creation-details.html for information).

\section{Electronic searches}

We searched the following electronic databases:

- Cochrane Oral Health's Trials Register (searched 2 June 2016) (Appendix 1);

- Cochrane Central Register of Controlled Trials (CENTRAL; 2016, Issue 5) in the Cochrane Library (searched 2 June 2016) (Appendix 2);

- MEDLINE Ovid (1946 to 2 June 2016) (Appendix 3);

- EMBASE Ovid (1980 to 2 June 2016) (Appendix 4).

No restrictions were placed on the language or date of publication when searching the electronic databases.

\section{Searching other resources}

We searched the following trial registries for ongoing studies (see Appendix 5 for information on the search terms used):

- US National Institutes of Health Ongoing Trials Register ClinicalTrials.gov (ClinicalTrials.gov; searched 2 June 2016);

- the World Health Organization International Clinical Trials Registry Platform (apps.who.int/trialsearch; searched 2 June 2016).

All the first authors of trial reports were contacted in an attempt to identify any unpublished studies and clarify information about the published trials (including missing data, method of randomisation, blinding and withdrawals).

Manufacturers were contacted to confirm the cement/adhesive type and were also asked about their knowledge of any unpublished or ongoing clinical trials or both.

Only handsearching done as part of the Cochrane Worldwide Handsearching Programme and uploaded to CENTRAL was included.

We searched the reference lists of included studies and relevant systematic reviews for further studies.

\section{Data collection and analysis}

(1) All review authors were involved in study selection, validity assessment and data extraction without blinding to the authors, adhesives used or results obtained.

(2) The selection of papers, decision about eligibility and data extraction were carried out independently by all members of the review team. All disagreements were resolved by discussion.

A statistician was to be consulted with regard to data analysis and where doubt existed about inclusion.

(3) The following data were entered on a customised data collection form. 
- Date that the study was conducted.

- Year of publication.

- Treatments including details of type of adhesive used to cement molar bands and type of fixed appliance used.

- Sample size by study group.

- Age of subjects.

- Number of male subjects and female subjects per study group.

- Details of withdrawals by study group.

- Outcome measures.

The primary outcome measures were band adhesive failure rate and decalcification. Data on adverse events (i.e. illness, allergy, bad taste), damage to teeth on band removal, length of treatment, treatment cost and time to replace bands with an adhesive were also recorded.

(4) The quality of eligible trials was assessed according to the following criteria.

- Clarity of inclusion and exclusion criteria.

- Whether a sample size calculation was reported.

- Means used to calculate sample size.

- Method of allocation of randomisation.

- Concealment of randomisation.

- Whether groups were treated identically other than the named intervention.

- Completeness of follow-up.

- Details of how withdrawals were reported.

- Details of management of study dropouts.

- Blinding of clinicians, patients and outcome assessors.

\section{Assessment of the appropriateness of statistical analysis}

All eligible studies were assessed for the appropriateness of their analysis. The statistical analysis was considered inappropriate if:

(1) a split-mouth design did not take the clustering of the teeth or 'pairing' into account;

(2) all failures were included without taking into account multiple failures on the same tooth.

\section{Data synthesis}

Comparisons were made firstly between any of the six main types of adhesive. If possible, comparisons were to be made within groups and, where appropriate, between chemical and light-cured adhesives as follows:

(1) zinc phosphate cement - variables on powder and liquid (product is not light-cured);

(2) zinc silicophosphate cement - variables on powder and liquid (product is not light-cured);

(3) zinc polycarboxylate - variables on powder and liquid (product is not light-cured);

(4) glass ionomer cement - conventional (variables on glass and acid);

(5) polyacid-modified composite resin (compomer) - variables on composite matrix and glass ionomer particles;

(6) resin-modified glass ionomer cement - variables on type of acid, resin and polymerisation mechanism; and

(7) glass phosphonate - variables of type of glass, phosphonate.
Within group comparisons assessing products of different brand names to see if any adhesive of the same type performs better than another of the same type, were also to be undertaken if data allowed.

The following data synthesis was planned if data allowed.

(1) Heterogeneity was to be assessed by inspection of a graphical display of the estimated treatment effects from the trials along with their 95\% confidence intervals and by Cochran's test for homogeneity undertaken before each meta-analysis. Any heterogeneity was to be investigated.

(2) Meta-analyses were to be undertaken only on studies of similar comparisons reporting the same outcome measures. The Cochrane Statistical Methods Group guidelines were to be followed, calculating risk ratios along with $95 \%$ confidence intervals and they were to be combined using a random-effects model. The number needed to treat (NNT) was to be calculated to prevent one extra band failing, as appropriate.

(3) Heterogeneity was to be investigated for aspects of study quality and for potential sources of heterogeneity specified a priori as follows: excluding/including unpublished studies, excluding/ including studies of low quality and excluding/including one or more large studies to assess how much they dominate the results. Identification of studies of low quality was undertaken using the criteria given in the Cochrane Handbook for Systematic Reviews of Interventions (Higgins 2006). The association of these factors with estimated effects was to be examined by performing random-effects metaregression analysis in Stata version 7.0 (Stata Corporation, USA), using the program Metareg. Further potential sources of heterogeneity were to be investigated as determined from the study reports, although these would have been clearly identified as 'post-hoc' analyses and the results treated with caution.

\section{RES U LTS}

\section{Description of studies}

Five randomised controlled trials (RCTs) (Clark 2003; Gillgrass 2001; Kvam 1983; Stirrups 1991; Williams 2005) and three controlled clinical trials (CCTs) (Durning 1989; Fricker 1997; Galarraga 2003) were identified as meeting the review's inclusion criteria with regard to study design, participants, intervention and outcome. A description of each trial is presented in the Characteristics of included studies table.

\section{Study design}

All the included trials were of split-mouth design. In four of the trials diagonally opposing first molars were randomly allocated to a single adhesive (i.e. upper right/lower left receive adhesive $A$, and upper left/lower right received adhesive B) (Clark 2003; Gillgrass 2001; Stirrups 1991; Williams 2005). In one trial only upper first molars were included and the adhesives randomly allocated to either the left or right of the mouth (Kvam 1983). In a fifth trial, both upper and lower molars were included but the adhesives were allocated "on a rotational basis" to either the left or right of the mouth (Fricker 1997). Galarraga and Croce (Galarraga 2003) allocated one adhesive to the right side of the mouth and the other adhesive to the left hand-side. Durning 1989 alternated between left and right when allocating the adhesives. 


\section{Participants}

All participants required fixed appliance therapy. The gender mix was only stated in four trials (Clark 2003; Durning 1989; Galarraga 2003; Gillgrass 2001) and only three trials reported participants age (mean pretreatment age for males was 19.1 years (standard deviation (SD) 3.7 years) and 17.8 years (SD 3.0 years) for females (Gillgrass 2001); 13 to 19 years (Galarraga 2003); mean age 15.23 years (SD 3.41 years) (Durning 1989)).

\section{Interventions}

Adhesive type:

\section{- Zinc phosphate cement}

Four trials compared chemically cured zinc phosphate and chemically cured glass ionomer (Durning 1989; Galarraga 2003; Kvam 1983; Stirrups 1991).

\section{- Glass ionomer cement}

Four trials compared chemically cured glass ionomer and chemically cured zinc phosphate (Durning 1989; Galarraga 2003; Kvam 1983; Stirrups 1991). Two trials compared chemically cured glass ionomer cement with light-cured compomer (Fricker 1997; Gillgrass 2001). The trial by Fricker and colleagues had a third comparison arm of light-cured resin-modified glass ionomer (Fricker 1997). One trial compared chemically cured glass ionomer with a chemically cured glass phosphonate (Clark 2003).

\section{- Polyacid-modified composite resin (compomer)}

Two trials compared light-cured compomer with chemically cured glass ionomer (Fricker 1997; Gillgrass 2001). The trial by Fricker and colleagues had a third comparison arm of light-cured resinmodified glass ionomer (Fricker 1997). A third trial compared light-cured compomer with chemically cured resin-modified glass poly(alkenoate) cement (Williams 2005).

\section{- Resin-modified glass ionomer cement}

Only one trial included a light-cured, resin-modified glass ionomer and compared it with a light-cured compomer and a chemically cured glass ionomer (Fricker 1997). A second trial compared a chemically cured resin-modified glass poly(alkenoate) cement with a light-cured polyacid-modified composite resin (compomer) (Williams 2005).

No trial was identified that examined the effectiveness of zinc silicophosphate cement or zinc polycarboxylate.

\section{Outcomes}

All trials reported failure, typically defined as band loosening. Only two trials stated the date used for assessment of failure, with one trial recording the date the patient returned for band recementation (Gillgrass 2001) and another recording the date the patient became aware of band loosening (Stirrups 1991).

Only two trials clearly reported follow up of patients until the end of the treatment period (Galarraga 2003; Gillgrass 2001). In one study the observation period was unclear (Stirrups 1991).

\section{Risk of bias in included studies}

Additional Table 1 presents the results of the validity assessment.

The generation of the random number sequence was considered adequate in only three trials (Clark 2003; Stirrups 1991; Williams 2005). All three trials used a random numbers table. The generation of the sequence was unclear in three trials (Galarraga 2003; Gillgrass 2001; Kvam 1983) and in the other trials adhesives were allocated using a quasi-random method (Durning 1989; Fricker 1997).

Only one of the trials reported adequate allocation concealment (Williams 2005) and in none of the trials was it clear whether outcome assessment was truly blind. Only one of the trials reported an a priori sample size calculation (Williams 2005).

In four trials there were no dropouts (Clark 2003; Durning 1989; Kvam 1983; Williams 2005). In two trials the number of drop outs was clearly described although the reasons were not reported (Galarraga 2003; Gillgrass 2001). In two trials, the number of dropouts was unclear (Fricker 1997; Stirrups 1991).

\section{Effects of interventions}

A total of 24 trials were deemed to be potentially relevant to the review and full articles of these trials were retrieved. Following subsequent assessment of the papers only eight were found to meet the inclusion criteria (Clark 2003; Durning 1989; Fricker 1997; Galarraga 2003; Gillgrass 2001; Kvam 1983; Stirrups 1991; Williams 2005); 16 were excluded for reasons listed under Characteristics of excluded studies. For five trials, the study design was unclear and the authors have been contacted (Dincer 2002; Fricker 1985; Fricker 1987; Maijer 1988; Seeholzer 1988). These studies will be excluded until further clarification is received.

Data analysis was not always appropriate within the studies meeting the inclusion criteria.

\section{Chemically cured zinc phosphate and chemically cured glass ionomer}

Four trials compared chemically cured zinc phosphate and chemically cured glass ionomer (Durning 1989; Galarraga 2003; Kvam 1983; Stirrups 1991). However, Stirrups 1991 presented failure of bands by site (upper/lower, right/left molars) but information as to the number of patients experiencing a failed band is not presented. Galarraga and Croce (Galarraga 2003) recruited 40 participants. A total of 160 bands were placed. The data regarding the number of lost, loose or broken bands are not presented at a patient level. However, data regarding demineralisation show that a total of eight participants experienced demineralisation (one with glass ionomer only, four with zinc phosphate only and three with both adhesives).

Kvam 1983 recruited 28 participants. In each patient one molar band was cemented with a chemically cured zinc phosphate and one cemented with glass ionomer cement. No band loosenings were identified for either cement type at 1 year. When teeth were examined for decalcification, four teeth were affected with small spots that were reversed by polishing and fluoride application. All cases occurred with the zinc phosphate cement.

Durning 1989 recruited 69 participants. Two bands were placed in each participant; one band was cemented using a chemically cured zinc phosphate and one cemented with glass ionomer cement. 
Allocation was determined by alternation. The author reports that at approximately 12 months the failure rate was $34.78 \%$ for bands cemented with zinc phosphate and $26 \%$ for bands cemented with glass ionomer $(P>0.05)$. No statistically significant difference was seen with regard to mean survival time between the cemented band groups ( 470.9 days versus 523.6 days for zinc phosphate and glass ionomer respectively).

\section{Chemically cured glass ionomer cement with light-cured compomer}

Three trials compared chemically cured glass ionomer cement with light-cured compomer (Fricker 1997; Gillgrass 2001; Williams 2005). The data from Fricker 1997 are not presented in an appropriate format. Although failure rates are presented, neither the number of bands per person or the number of failures per person are presented. Gillgrass 2001 compared chemically cured glass ionomer cement with light-cured compomer in a split-mouth study (98 participants; 140 band pairs). Four participants had a single band fail when attached using chemically cured glass ionomer cement (Ketac-Cem) compared to seven band failures (in seven participants) for those attached with the light-cured compomer (Band-Lok). The authors of the trial report that a comparison of changes in mean enamel white spot lesion scores during treatment showed no statistically significant difference between the two cement types $(P=0.16)$.

A third trial compared chemically cured glass ionomer cement with light-cured polyacid-modified composite resin (Williams 2005). The study was split-mouth in design, with 30 participants receiving a total of 120 bands (60 with each band adhesive). Data on the number of failures per patient are not presented; however, the number of failures was very low for each band adhesive over the initial 12-month assessment period (two failures with the glass ionomer; one failure with the composite resin). A statistically significant difference, in favour of the glass ionomer, was seen for patient preference with regard to taste.

\section{Chemically cured glass ionomer with a chemically cured glass phosphonate}

One trial compared chemically cured glass ionomer with a chemically cured glass phosphonate (Clark 2003). Data are presented for failure rates for each adhesive group, based on the number of bands failing in each group (overall proportion of band failure for each material was 0.048). However, there are no data provided for the number of failures on a patient basis. There was also no statistically significant difference between the taste of the two cements but the authors caution this finding as both cements were used at the same sitting with the possibility that the taste of one cement may have affected that of the other.

\section{I S C U S S I O N}

Following application of the exclusion criteria adopted for this review, four of the eight trials identified compared chemically cured zinc phosphate with chemically cured glass ionomer. Fewer studies made comparison of chemically cured glass ionomer with light-cured compomer or chemically cured glass phosphonate. Five studies were excluded because they did not compare two band adhesives and a further seven studies were removed because the study design was unclear or has not been clarified to date by the authors. It is disappointing that several authors did not present the study plan in greater detail.
Of the included studies, band failure has been reported for each adhesive group (Clark 2003; Fricker 1997; Williams 2005) or per site (Stirrups 1991) but not on a per patient basis. This precluded the undertaking of a meta-analysis.

The method of randomisation was only adequate in three of the included trials. In the four other trials, the risk of bias would be regarded as moderate to high (Additional Table 1). In one trial, allocation concealment was adequate with sealed envelopes being used for cement and quadrant allocation (Williams 2005). Blinding the operator to outcome assessment was unclear in all trials. Regretably, a sample size calculation was only reported in one trial (Williams 2005). Five studies had no dropouts; one dropout occurred in one trial but the number of dropouts was not adequately clarified in two trials.

Furthermore insufficient reporting of band failure rate was made in all studies. Greater care is required to ensure that the statistical analyses are most appropriate for the trial design adopted. Splitmouth trials can be used when the adhesives being assessed do not release an agent that could influence failure or decalcification. However, where a split-mouth design is used, the mean failure rate or mean survival time per band adhesive type per patient should be reported along with standard deviation or 95\% confidence intervals. Where individual patients are allocated to one or other band adhesive type, then the outcome data with respect to adhesive failure /survival should be reported in the same manner.

Only two trials report outcome assessment at the completion of the treatment period (Galarraga 2003; Gillgrass 2001). A previously published systematic review examining the effectiveness of adhesives for fixed orthodontic brackets excluded all trials that did not follow patients until the end of the appliance treatment period (Mandall 2003). Whilst the current review has been less restrictive in its inclusion criteria, future trials should report outcomes following the completion of treatment to enable a more objective assessment of the effectiveness of one band adhesive over another.

\section{Qualitative comparison of orthodontic band adhesives}

Due to the inherent bias in most of the study designs, the information from those included in this review should be interpreted with great caution. From the limited information available, only suggestions in the broadest sense are possible.

\section{Chemically cured zinc phosphate versus chemically cured glass ionomer}

There is insufficient evidence to support or refute the use of one adhesive (chemically cured zinc phosphate or glass ionomer) over the other with regard to band failure (Durning 1989; Galarraga 2003; Kvam 1983; Stirrups 1991). Trials did not present data at the patient level (Galarraga 2003; Stirrups 1991); identified no band loosening at 12 months (Kvam 1983); or showed no statistically significant difference between groups (Durning 1989).

There is weak evidence from two trials (Galarraga 2003; Kvam 1983) that there is less decalcification on teeth where bands had been cemented with glass ionomer rather than zinc phosphate (no statistical analysis was undertaken in either trial). 
Chemically cured glass ionomer cement versus light-cured compomer (poly-acid modified composite)

Again, there is insufficient evidence to support or refute the use of one adhesive (chemically cured glass ionomer or light-cured componer) over the other with regard to band failure (Fricker 1997; Gillgrass 2001; Williams 2005). One trial presented data in an inappropriate format (Fricker 1997); two trials showed low band failure rates for both adhesives (Gillgrass 2001; Williams 2005), although one of the trials did not present the number of failures per person (Williams 2005).

There is weak evidence from one trial that there is no statistically significant difference in enamel decalcification with either cement (Gillgrass 2001).

\section{Chemically cured glass ionomer with a chemically cured glass phosphonate}

One trial compared chemically cured glass ionomer with a chemically cured glass phosphonate. Low band failure rates were recorded; however, there is insufficient evidence to support or refute the use of one adhesive over the other (Clark 2003).

\section{Reporting quality}

Concealment allocation was particularly poor in the trials included, with only one trial reporting this. There were overall high rates of patient follow-up which suggest that it is possible to minimize sample attrition bias in trials of orthodontic band adhesives. However, in two trials the number of dropouts was unclear. Blinding to the study outcome measure(s) was also very poorly reported.

Provided the band adhesives being compared had the same curing mechanism and mixing requirements, then blinding of patient and operator to the adhesive type would be possible. Where different curing mechanisms exist between the two adhesives being compared, blinding of the patient only could be done if the explanations were carried out carefully.

\section{AUTHORS' CONCLUSIONS}

\section{Implications for practice}

There is insufficient evidence to make firm recommendations for the use of one band adhesive over another.

\section{Implications for research}

In view of the poor quality of the trials identified for this systematic review, conclusions cannot be drawn. However, in designing future trials, the following should be considered.

- Clear inclusion/exclusion criteria should be set.

- Involvement of a statistician in study design (single blind or double blind if feasible), sample size calculation and projected data analyses.

- Allocate a single adhesive per patient, rather than a split-mouth study with two adhesives per patient, if either adhesive releases an agent that could influence failure or decalcification.

- Treatment, except for the intervention, should be similar for each trial subject.

- Occlusal interferences that may affect band failure should be recorded.

- Patients should be followed to the end of treatment.

- All dropouts and withdrawals should be recorded and included in any analysis.

- The failure rate of each adhesive and the change in decalcification score with treatment should be presented on a per patient basis.

- Assessors should be calibrated with regard to assessment of decalcification.

- Include standard deviation (or 95\% confidence interval (CI)) with mean number of failures or mean survival time for each adhesive system.

\section{ACKNOWLEDGEMENTS}

We would like to thank Helen Worthington for her assessment of the suitability of the data from the trial reports for inclusion. We also thank Sylvia Bickley, Emma Tavender and Luisa Fernandez Mauleffinch for their kind assistance with the literature searches and for their help with completing the review. We also thank referees for their helpful comments. 


\section{RE F E R E N C E S}

\section{References to studies included in this review}

Clark 2003 \{published data only\}

Clark JR, Ireland AJ, Sherriff M. An in vivo and ex vivo study to evaluate the use of a glass polyphosphonate cement in orthodontic banding. European Journal of Orthodontics 2003;25(3):319-23.

\section{Durning 1989 \{unpublished data only\}}

Durning P. A clinical and laboratory investigation into the cements used to retain orthodontic bands [dissertation]. Newcastle-upon-Tyne, UK: University of Newcastle-upon-Tyne, 1989.

\section{Fricker 1997 \{published data only\}}

Fricker JP. A 12-month clinical comparison of resin-modified light-activated adhesives for the cementation of orthodontic molar bands. American Journal of Orthodontics and Dentofacial Orthopedics 1997;112(3):239-43.

\section{Galarraga 2003 \{published data only\}}

Galarraga NR, Croce N. Comparative clinical trials between orthodontic band cements with zinc phostate and conventional glass ionomer [Estudio clínico comparativo entre el cementado de bandas ortodóncicas con fosfato de zinc y con vidrio ionomérico convencional]. Latin American Journal of Orthodontics and Pediatric Dentistry - www.ortodoncia.ws 2003.

\section{Gillgrass 2001 \{published data only\}}

Gillgrass TJ, Benington PC, Millett DT, Newell J, Gilmour WH. Modified composite or conventional glass ionomer for band cementation? A comparative clinical trial. American Journal of Orthodontics and Dentofacial Orthopedics 2001;120(1):49-53.

Kvam 1983 \{published data only\}

Kvam E, Broch J, Nissen-Meyer IH. Comparison between a zinc phosphate cement and a glass ionomer cement for cementation of orthodontic bands. European Journal of Orthodontics 1983;5(4):307-13.

\section{Stirrups 1991 \{published data only\}}

Stirrups DR. A comparative clinical trial of a glass ionomer and a zinc phosphate cement for securing orthodontic bands. British Journal of Orthodontics 1991;18(1):15-20.

\section{Williams 2005 \{published data only\}}

Williams PH, Sherriff M, Ireland AJ. An investigation into the use of two polyacid-modified composite resins (compomers) and a resin-modified glass poly(alkenoate) cement used to retain orthodontic bands. European Journal of Orthodontics 2005;27:245-51.

\section{References to studies excluded from this review}

Adriaens 1990 \{published data only\}

Adriaens ML, Dermaut LR, Verbeeck RM. The use of 'Fluor Protector', a fluoride varnish, as a caries prevention method under orthodontic molar bands. European Journal of Orthodontics 1990;12(3):316-9.

\section{Akkaya \{published data only\}}

Akkaya S, Uner O, Alacam A, Degim T. Enamel fluoride levels after orthodontic band cementation with glass ionomer cement. European Journal of Orthodontics 1996;18(1):81-7.

Dincer 2002 \{published data only\}

Dincer B, Erdinc AM. A comparison between zinc polycarboxylate and glass ionomer cement in the orthodontic band cementation. Journal of Clinical Pediatric Dentistry 2002;26(3):285-8.

\section{Fricker 1985 \{published data only\}}

Fricker JP, McLachlan MD. Clinical studies of glass ionomer cements. Part I--A twelve month clinical study comparing zinc phosphate cement to glass ionomer. Australian Orthodontic Journal 1985;9(1):179-80.

\section{Fricker 1987 \{published data only\}}

Fricker JP, McLachlan MD. Clinical studies on glass ionomer cements. Part 2--A two year clinical study comparing glass ionomer cement with zinc phosphate cement. Australian Orthodontic Journal 1987;10(1):12-4.

Fricker 1989 \{published data only\}

Fricker JP. A 12-month clinical study comparing four glass ionomer cements for the cementation of orthodontic molar bands. Australian Orthodontic Journal 1989;11(1):10-3.

Glasspoole 2001 \{published data only\}

Glasspoole EA, Erickson RL, Davidson CL. Demineralization of enamel in relation to the fluoride release of materials. American Journal of Dentistry 2001;14(1):8-12.

Gorelick 1982 \{published data only\}

Gorelick L, Geiger AM, Gwinnett AJ. Incidence of white spot formation after bonding and banding. American Journal of Orthodontics 1982;81(2):93-8.

Maijer 1988 \{published data only\}

Maijer R, Smith DC. A comparison between zinc phosphate and glass ionomer cement in orthodontics. American Journal of Orthodontics and Dentofacial Orthopedics 1988;93(4):273-9.

Mizrahi 1979 \{published data only\}

Mizrahi E. Retention of orthodontic bands using polycarboxylate cements. Journal of Dental Research 1979;58(Special Issue C):1302 (Abs 9).

Mizrahi 1979a \{published data only\}

Mizrahi E. Retention of the conventional orthodontic band British Journal of Orthodontics 1977;4(3):133-7.

Neumann 1976 \{published data only\}

Neumann HF. A clinical evaluation of decalcification under orthodontic bands following pretreatment with acidulated 
phosphate-fluorides and adhesive plastic coatings. American Journal of Orthodontics 1976;69(6):698-9.

\section{Norris 1986 \{published data only\}}

Norris DS, Mclnnes-Ledoux P, Schwaninger B, Weinberg R. Retention of orthodontic bands with new fluoride-releasing cements. American Journal of Orthodontics 1986;89(3):206-11.

\section{Rezk-Lega 1991 \{published data only\}}

Rezk-Lega F, Ogaard B, Arends J. An in vivo study on the merits of two glass ionomers for the cementation of orthodontic bands. American Journal of Orthodontics and Dentofacial Orthopedics 1991;99(2):162-7.

\section{Seeholzer 1988 \{published data only\}}

Seeholzer HW, Dasch W. Banding with a glass ionomer cement. Journal of Clinical Orthodontics 1988;22(3):165-9.

\section{van der Linden 1998 \{published data only\}}

van der Linden RP, Dermaut LR. White spot formation under orthodontic bands cemented with glass ionomer with or without Fluor Protector. European Journal of Orthodontics 1998;20(3):219-24.

\section{Additional references}

\section{Brown 1989}

Brown D. Orthodontic materials update. Orthodontic band cements. British Journal of Orthodontics 1989;16:127-31.

\section{DPB 2002}

Dental Practice Board (DPB). Statistical Department, Compton Place Rd, Eastbourne, East Sussex. 2002.

\section{Durning 1994}

Durning P, McCabe JF, Gordon PH. A laboratory investigation into cements used to retain orthodontic bands. British Journal of Orthodontics 1994;21:27-32.

\section{Evans 1987}

Evans R, Shaw WC. Preliminary evaluation of an illustrated scale for rating dental attractiveness. European Journal of Orthodontics 1987;9:314-8.

\section{Gottlieb 1996}

Gottlieb EL, Nelson AH, Vogels DS. 1996 JCO study of orthodontic diagnosis and treatment procedures. Part 1. Results and trends. Journal of Clinical Orthodontics 1996;30(11):615-29.

\section{Higgins 2006}

Higgins JPT, Green S, editors. Cochrane Handbook for Systematic Reviews of Interventions 4.2.6 [updated September 2006]. The Cochrane Library, Issue 4. Chichester, UK: John Wiley \& Sons, Ltd, 2006.

\section{Higgins 2011}

Higgins JP, Green S, editor(s). Cochrane Handbook for Systematic Reviews of Interventions Version 5.1.0 (updated
March 2011). The Cochrane Collaboration, 2011. Available from handbook.cochrane.org.

\section{Hodges 2001}

Hodges SJ, Gilthorpe MS, Hunt NP. The effect of microetching on the retention of orthodontic molar bands: a clinical trial. European Journal of Orthodontics 2001;23:91-7.

\section{Holmes 1992}

Holmes A. The prevalence of orthodontic treatment need. British Journal of Orthodontics 1992;19:177-82.

\section{Keim 2002a}

Keim RG, Gottlieb EL, Nelson AH, Vogels DS. 2002 JCO study of orthodontic diagnosis and treatment procedures. Part 2. Breakdowns of selected variables. Journal of Clinical Orthodontics 2002;36(11):627-36.

\section{Keim 2002b}

Keim RG, Gottlieb EL, Nelson AH, Vogels DS. 2002 JCO study of orthodontic diagnosis and treatment procedures. Part 1. Results and trends. Journal of Clinical Orthodontics 2002;36(10):553-68.

\section{Mandall 2003}

Mandall NA, Millett DT, Mattick CR, Hickman J, Macfarlane TV, Worthington HV. Adhesives for fixed orthodontic brackets. Cochrane Database of Systematic Reviews 2003, Issue 2. [DOI: 10.1002/14651858.CD002282]

\section{McCabe 1998}

McCabe JF. Resin-modified glass ionomers. Biomaterials 1998;19:521-7.

\section{Millett 1992}

Millett DT, Gordon PH. Perfomance of first molar bands cemented with glass ionomer cement. British Journal of Orthodontics 1992;19:215-20.

\section{O'Brien 1993}

O'Brien KD, Shaw WC, Roberts CT. The use of occlusal indices in assessing the provision of orthodontic treatment by the hospital service of England and Wales. British Dental Journal 1993;20:25-35.

\section{Panula 2002}

Panula K, Keshi-Nisula L, Keski-Nisula K, Oilarinen K, KeskiNisula S. Costs of surgical-orthodontic treatment in community hospital care: an analysis of the different phases of treatment. International Journal of Adult Orthodontics and Orthognathic Surgery 2002;17:297-306.

\section{Pietila 1998}

Pietila T, Sintonen H, Pietila I, Widstrom E, Varella J, Alanen P. Cost and productivity analysis of orthodontic care in Finland. Community Dentistry and Oral Epidemiology 1998;26:283-8.

\section{Richmond 1993}

Richmond S, Shaw WC, Stephens CD, Webb WG, Roberts CT, Andrews M. Orthodontics in the General Dental Service of England and Wales. British Dental Journal 1993;174:315-29. 


\section{Russell 1999}

Russell JI, Pearson Al, Bowden DEJ, Wright J, O'Brien KD. The Consultant Orthodontic Service - 1998 Survey. British Dental Journal 1999;187:149-53.

\section{Stirrups 1991}

Stirrups DR. A comparative trial of a glass ionomer and a zinc phosphate cement for securing orthodontic bands. British Journal of Orthodontics 1991;18:15-20.

\section{CHARACTERISTICS OF STUDIES}

Characteristics of included studies [ordered by study ID]

\section{Øilo 1991}

Øilo G. Luting cements: a review and comparison. International Dental Journal 1991;41(2):81-8.

\section{References to other published versions of this review \\ Millett 2006}

Millett DT, Glenny AM, Mattick CR, Hickman J, Mandall NA. Adhesives for fixed orthodontic bands. Cochrane Database of Systematic Reviews 2006, Issue 3. [DOI: 10.1002/14651858.CD004485.pub2]

Clark 2003

\begin{tabular}{ll}
\hline Methods & $\begin{array}{l}\text { RCT, split-mouth design. } \\
\text { 6-month observation period. }\end{array}$ \\
\hline Participants & $\begin{array}{l}\text { 31 consecutive participants undergoing 2-arch fixed appliance therapy, 124 bands to first molars. } \\
\text { M/F 14/17. } \\
\text { Age not stated. }\end{array}$ \\
\hline Interventions & $\begin{array}{l}\text { Gp 1. Glass phosphonate cement, Diamond, KemDent Associated Dental Products Ltd. Chemical curing } \\
\text { (62 bands). }\end{array}$ \\
\hline Gp 2. Glass polyalkenoate cement, Ketac-Cem, ESPE America Inc. Chemical curing (62 bands). \\
\hline Outcomes & Band failure (not defined) and taste. \\
\hline Risk of bias & $\begin{array}{l}\text { Overall treatment time not stated. } \\
\text { Data on number of failures per patient not known. }\end{array}$ \\
\hline Bias & Authors' judgement Support for judgement \\
\hline $\begin{array}{l}\text { Allocation concealment } \\
\text { (selection bias) }\end{array}$ & Unclear risk \\
\hline
\end{tabular}

Durning 1989

$\begin{array}{ll}\text { Methods } & \text { CCT, split-mouth design. } \\ & 12 \text {-month observation period. }\end{array}$

Participants
M/F 27/42.
Mean age 15.23 (SD 3.41) years.

Interventions Gp 1. Zinc phosphate, Orthocent, Espe Gmbh. Chemical curing (69 bands).

Gp2. Glass ionomer, Ketac-Cem, Espe Gmbh. Chemical curing (62 bands)

Outcomes Band failure defined as band loosening.

Notes 
Durning 1989 (Continued)

Risk of bias

\begin{tabular}{lll}
\hline Bias & Authors' judgement & Support for judgement \\
\hline $\begin{array}{l}\text { Allocation concealment } \\
\text { (selection bias) }\end{array}$ & Unclear risk & D - Not used \\
\hline
\end{tabular}

Fricker 1997

\begin{tabular}{ll}
\hline Methods & CCT, split-mouth design. \\
& 1 year observation period. \\
\hline Participants & $\begin{array}{l}50 \text { consecutive participants, } 188 \text { bands to first molars. } \\
\text { M/F not stated. } \\
\text { Age not stated. }\end{array}$
\end{tabular}

Interventions
Gp 1. Resin-modified glass ionomer, Fuji II LC, GC Int. Light activated dual cure (69 bands).
Gp 2. Resin with added glass, Bandlok, Reliance Orthodontic Products. Light activated dual cure (62
Gp 3. Glass ionomer cement, Ketac-Cem, ESPE America Inc. Chemical curing (57 bands).
2 of the 3 cements were selected for each patient by the chairside assistant on a rotational basis.

Outcomes $\quad$ Failure defined as loose molar band. Weld failures requiring recementation and/or transfer of patient
to another practice were removed from the sample.

\begin{tabular}{|c|c|c|}
\hline Notes & Data on number of ba & ds per patient or number of failures per patient not known. \\
\hline \multicolumn{3}{|l|}{ Risk of bias } \\
\hline Bias & Authors' judgement & Support for judgement \\
\hline $\begin{array}{l}\text { Allocation concealment } \\
\text { (selection bias) }\end{array}$ & High risk & C-Inadequate \\
\hline
\end{tabular}

\section{Galarraga 2003}

\begin{tabular}{ll}
\hline Methods & RCT, split-mouth design. Mean treatment period of 26.1 months. \\
\hline Participants & 40 participants, 80 pairs of bands to first permanent molars. \\
M/F $14 / 24$ (data not available for 1 participant). \\
Age 13 to 19 years.
\end{tabular}

\begin{tabular}{ll}
\hline Interventions & Gp 1. Zinc phosphate. Assumed chemical curing ( 80 bands). \\
Gp 2. Glass ionomer. Assumed chemical curing ( 80 bands).
\end{tabular}

\begin{tabular}{ll}
\hline Outcomes & Failure defined as lost, loose or broken. \\
\hline Notes & Data taken from translation (Country of origin: Venezuela).
\end{tabular}

\section{Risk of bias}

Bias Authors' judgement Support for judgement


Galarraga 2003 (Continued)

Allocation concealment $\quad$ Unclear risk $\quad$ B - Unclear
(selection bias)

Gillgrass 2001

$\begin{array}{ll}\text { Methods } & \text { RCT, split-mouth design. } \\ \text { Observed for duration of treatment (mean } 20.3 \text { months) time. }\end{array}$

Participants
$\begin{array}{ll}\text { M/F } 32 / 66 . \\ \text { Mean pretreatment ages (M/F) } 19.1 \text { years (SD 3.7) / } 17.8 \text { years (SD 3.0). }\end{array}$

\begin{tabular}{ll}
\hline Interventions & Gp 1. Modified composite, Band-Lok. Light cured (140 bands). \\
Gp 2. Conventional glass ionomer, Ketac-Cem Chemically cured (140 bands). \\
In all participants, preadjusted edgewise appliances were used.
\end{tabular}

Outcomes

Band failure defined as band loosening. Failure date recorded as the day the patient returned for recementation.

Notes

\section{Risk of bias}

\begin{tabular}{lll}
\hline Bias & Authors' judgement & Support for judgement \\
\hline $\begin{array}{l}\text { Allocation concealment } \\
\text { (selection bias) }\end{array}$ & Unclear risk & B - Unclear \\
\hline
\end{tabular}

\section{Kvam 1983}

\begin{tabular}{ll}
\hline Methods & $\begin{array}{l}\text { RCT, split-mouth design. } \\
1 \text { year observation period. }\end{array}$ \\
\hline Participants & $\begin{array}{l}\text { 28 participants, } 56 \text { bands to first upper molars. 2\% neutral NaF applied prior to cementation. } \\
\text { M/F not stated. } \\
\text { Age not stated ("Young patients"). }\end{array}$ \\
\hline Interventions & Gp 1. Fine grain phosphate cement. Manufacturer not stated. Assumed chemical curing (28 bands). \\
& Gp 2. Glass ionomer. Manufacturer not stated. Assumed chemical curing (28 bands). \\
\hline Outcomes & Gingival, plaque, enamel and cement indices. \\
& $\begin{array}{l}\text { Definition of band failure unclear. Visual examination for demineralisation (enamel index graded } 0 \text { to } \\
\text { 3). }\end{array}$
\end{tabular}

\section{Notes}

\section{Risk of bias}

\begin{tabular}{lll}
\hline Bias & Authors' judgement & Support for judgement \\
\hline $\begin{array}{l}\text { Allocation concealment } \\
\text { (selection bias) }\end{array}$ & Unclear risk & B - Unclear \\
\hline
\end{tabular}


Stirrups 1991

\begin{tabular}{ll} 
Methods & RCT, split-mouth design. \\
& Observation period/treatment time not stated. \\
\hline Participants & $\begin{array}{l}142 \text { consecutive participants, } 568 \text { bands cemented to first molars. } \\
\text { M/F not stated. } \\
\text { Age not stated. }\end{array}$
\end{tabular}

\begin{tabular}{ll}
\hline Interventions & $\begin{array}{l}\text { Gp 1. Experimental glass ionomer, Dentsply Ltd. Curing mechanism unclear (284 bands). } \\
\text { Gp 2. Zinc phosphate, OrthoGold, Orhtomax Ltd. Chemical cured (284 bands). }\end{array}$ \\
\hline Outcomes & $\begin{array}{l}\text { Failure defined as loose band. Failure date recorded as day patient became aware of loosening (where } \\
\text { possible). }\end{array}$
\end{tabular}

Notes No information as to the number of patients experiencing a failed band.

\section{Risk of bias}

\begin{tabular}{lll}
\hline Bias & Authors' judgement & Support for judgement \\
\hline $\begin{array}{l}\text { Allocation concealment } \\
\text { (selection bias) }\end{array}$ & Unclear risk & B - Unclear \\
\hline
\end{tabular}

Williams 2005

\begin{tabular}{ll}
\hline Methods & RCT, split-mouth design. \\
& 1 year observation period. \\
\hline Participants & 30 participants, 120 bands to first permanent molars. \\
M/F not stated. \\
Age not stated.
\end{tabular}

\begin{tabular}{ll}
\hline Interventions & Gp 1. Polyacid-modified composite resins (compomers). Light cured (60 bands). \\
Gp 2. Resin-modified glass poly(alkenoate) cement. Chemically cured (60 bands).
\end{tabular}

\begin{tabular}{|c|c|c|}
\hline Outcomes & \multicolumn{2}{|c|}{ Band failure (not defined) and taste. } \\
\hline Notes & \multicolumn{2}{|c|}{ Data on number of failures per patient not known, although failure rates very low. } \\
\hline \multicolumn{3}{|l|}{ Risk of bias } \\
\hline Bias & Authors' judgement & Support for judgement \\
\hline $\begin{array}{l}\text { Allocation concealment } \\
\text { (selection bias) }\end{array}$ & Low risk & A - Adequate \\
\hline
\end{tabular}

$\mathrm{CCT}=$ controlled clinical trial; $\mathrm{RCT}=$ randomised controlled trial; $\mathrm{SD}=$ standard deviation; $\mathrm{M} / \mathrm{F}=\mathrm{male} / \mathrm{female}$.

Characteristics of excluded studies [ordered by study ID] 


\begin{tabular}{|c|c|}
\hline Study & Reason for exclusion \\
\hline Adriaens 1990 & Not comparison of two adhesives. \\
\hline Akkaya & Outcome enamel fluoride concentrations. \\
\hline Dincer 2002 & Study design unclear. Authors contacted for clarification. \\
\hline Fricker 1985 & Awaiting clarification of study design from authors. \\
\hline Fricker 1987 & Awaiting clarification of study design from authors. \\
\hline Fricker 1989 & Not comparison of two adhesives. \\
\hline Glasspoole 2001 & In vitro. \\
\hline Gorelick 1982 & Not an RCT. \\
\hline Maijer 1988 & Study design unclear. Authors contacted for clarification. \\
\hline Mizrahi 1979 & Not an RCT. \\
\hline Mizrahi 1979a & Not comparison of two adhesives. \\
\hline Neumann 1976 & Not comparison of two adhesives. \\
\hline Norris 1986 & In vitro. \\
\hline Rezk-Lega 1991 & Premolars not molars. \\
\hline Seeholzer 1988 & Study design unclear. Authors contacted for clarification. \\
\hline van der Linden 1998 & Not comparison of two adhesives. \\
\hline
\end{tabular}

$\mathrm{RCT}=$ randomised controlled trial.

\section{ADDITIONAL TABLES}

Table 1. Validity assessment of included trials

\begin{tabular}{llllll}
\hline Trial & $\begin{array}{l}\text { Concealed al- } \\
\text { location }\end{array}$ & $\begin{array}{l}\text { Sequence gen- } \\
\text { eration }\end{array}$ & $\begin{array}{l}\text { Blind out- } \\
\text { come }\end{array}$ & Withdrawals & Risk of bias \\
\hline Clark 2003 & Unclear & Adequate & Unclear & No dropouts & Medium \\
\hline Durning 1989 & Not used & Inadequate & No & High & High \\
\hline Fricker 1997 & Inadequate & Inadequate & Unclear & No dropouts & High \\
\hline Galarraga 2003 & Unclear & Unclear & Unclear & $\begin{array}{l}\text { Onalysis } \\
\text { and - no intention-to-treat }\end{array}$ & High \\
\hline Gillgrass 2001 & Unclear & Unclear & Unclear & $\begin{array}{l}\text { Clear description but no inten- } \\
\text { tion-to-treat analysis }\end{array}$ \\
\hline
\end{tabular}


Table 1. Validity assessment of included trials (Continued)

\begin{tabular}{llllll} 
Kvam 1983 & Unclear & Unclear & Unclear & No dropouts & High \\
\hline Stirrups 1991 & Unclear & Adequate & Unclear & Unclear & Medium \\
\hline Williams 2005 & Adequate & Adequate & Unclear & No dropouts & Low \\
\hline
\end{tabular}

\section{APPENDICES}

\section{Appendix 1. Cochrane Oral Health's Trials Register search strategy}

From June 2016, searches of Cochrane Oral Health's Trials Register for this review were undertaken using the Cochrane Register of Studies and the search strategy below:

1 orthodontic:ti,ab

2 (brace* OR bracket* OR band $\left.{ }^{\star}\right):$ ti, ab

3 (composite* OR "Bisphenol-a-glycidyl-methacrylate" OR "polyacid-modified composite resin*" OR cement* OR bond* OR resin* OR compomer* OR "glass ionomer" OR adhesive*):ti,ab

4 \#1 and \#2 and \#3

Previous searches were undertaken using the Procite software and the search strategy below:

((orthodontic* AND (brace* OR bracket* OR band*)) AND (composite* OR "Bisphenol-a-glycidyl-methacrylate" OR "polyacid-modified composite resin ${ }^{\star}$ OR cement ${ }^{\star}$ OR bond ${ }^{\star}$ OR resin* OR compomer ${ }^{\star}$ OR "glass ionomer ${ }^{\star}$ " OR adhesive*))

\section{Appendix 2. The Cochrane Central Register of Controlled Trials (CENTRAL) search strategy}

\#1 ORTHODONTICS Explode all trees MeSH

\#2 orthodontic*

\#3 band*

\#4 ((\#1 or \#2) AND \#3)

\#5 COMPOSITE RESINS Explode all trees MeSH

\#6 GLASS IONOMER CEMENTS Explode all trees MeSH

\#7 RESIN CEMENTS single term MeSH

\#8 DENTAL BONDING Explode all trees MeSH

\#9 (resin* or cement ${ }^{\star}$ or bond ${ }^{\star}$ or (polyacid-modified next composite next resin) or compomer ${ }^{\star}$ or composite* or glass-ionomer ${ }^{\star}$ or adhesive $\left.{ }^{\star}\right)$

\#10 (\#5 or \#6 or \#7 or \#8 or \#9)

$\# 11$ (\#4 and \#10)

\section{Appendix 3. MEDLINE (Ovid) search strategy}

\section{1. $\exp$ ORTHODONTICS/}

2. orthodontic\$.mp. [mp=title, abstract, subject headings, heading word, drug trade name, original title, device manufacturer, drug manufacturer name]

3. band\$.mp. [mp=title, abstract, subject headings, heading word, drug trade name, original title, device manufacturer, drug manufacturer name]

4. $(1$ or 2$)$ and 3

5. exp Composite Resins/

6. exp Glass lonomer Cements/

7. Resin Cements/

8. exp Dental Bonding/

9. (resin\$ or cement\$ or bond\$ or "polyacid-modified composite resin\$" or compomer\$ or composite\$ or glass-ionomer\$ or adhesive

\$).mp.

10. or $/ 5-9$

11.4 and 10

The above subject search was linked to the Cochrane Highly Sensitive Search Strategy (CHSSS) for identifying randomised trials in MEDLINE: sensitivity maximising version (2008 revision) as referenced in Chapter 6.4.11.1 and detailed in box 6.4.c of theCochrane Handbook for Systematic Reviews of Interventions Version 5.1.0 [updated March 2011]. 
1. randomized controlled trial.pt.

2. controlled clinical trial.pt.

3. randomized.ab.

4. placebo.ab.

5. drug therapy.fs.

6. randomly.ab.

7. trial.ab.

8. groups.ab.

9. or/1-8

10. exp animals/ not humans.sh.

11.9 not 10

\section{Appendix 4. EMBASE (Ovid) search strategy}

1. exp Orthodontics/

2. orthodontic\$.mp.

3. band\$.mp.

4. (1 or 2$)$ and 3

5. (resin\$ or cement\$ or bond\$ or compomer\$ or composite\$ or glass ionomer\$ or glass-ionomer\$ or adhesive\$).mp.

6. Glass lonomer/

7. Resin/

8. dental bonding/

9. "polyacid-modified composite resin\$".mp.

10. or/5-9

11. 4 and 10

The above subject search was linked to adapted version of the Cochrane Embase Project filter for identifying RCTs in EMBASE via Ovid (see http://www.cochranelibrary.com/help/central-creation-details.html for information):

1. Randomized controlled trial/

2. Controlled clinical study/

3. Random\$.ti,ab.

4. randomization/

5. intermethod comparison/

6. placebo.ti,ab.

7. (compare or compared or comparison).ti.

8. ((evaluated or evaluate or evaluating or assessed or assess) and (compare or compared or comparing or comparison)).ab.

9. (open adj label).ti,ab.

10. ((double or single or doubly or singly) adj (blind or blinded or blindly)).ti,ab.

11. double blind procedure/

12. parallel group $\$ 1 . t i, a b$.

13. (crossover or cross over).ti,ab.

14. ((assign $\$$ or match or matched or allocation) adj5 (alternate or group $\$ 1$ or intervention $\$ 1$ or patient $\$ 1$ or subject $\$ 1$ or participant

\$1)).ti,ab.

15. (assigned or allocated).ti,ab.

16. (controlled adj7 (study or design or trial)).ti,ab.

17. (volunteer or volunteers).ti,ab.

18. trial.ti.

19. or/1-18

20. (exp animal/ or animal.hw. or nonhuman/) not (exp human/ or human cell/ or (human or humans).ti.)

21. 19 not 20

Appendix 5. ClinicalTrials.gov and WHO International Clinical Trials Registry Platform search strategy orthodontic and band

WHAT' S NEW

\begin{tabular}{lll}
\hline Date & Event & Description \\
\hline 1 November 2016 & Review declared as stable & $\begin{array}{l}\text { This review will not be updated until a substantial body of evi- } \\
\text { dence on the topic becomes available. If trials are conducted and }\end{array}$ \\
\hline Adhesives for fixed orthodontic bands (Review) &
\end{tabular}




\begin{tabular}{lll}
\hline Date & Description & \\
\hline & $\begin{array}{l}\text { found eligible for inclusion in the future, the review would then } \\
\text { be updated accordingly. }\end{array}$ \\
\hline
\end{tabular}

\section{HISTORY}

Protocol first published: Issue 4, 2003

Review first published: Issue 3, 2006

\begin{tabular}{lll}
\hline Date & Event & Description \\
\hline 21 September 2016 & New search has been performed & $\begin{array}{l}\text { An update search of all databases was conducted 2nd June 2016. } \\
\text { No additional studies were identified. }\end{array}$ \\
\hline 21 September 2016 & $\begin{array}{l}\text { New citation required but conclusions } \\
\text { have not changed }\end{array}$ & $\begin{array}{l}\text { New search, no new studies identified. Only search methods sec- } \\
\text { tions updated. Minor edits. }\end{array}$ \\
\hline 13 August 2008 & Amended & Converted to new review format. \\
\hline 21 February 2007 & New search has been performed & $\begin{array}{l}\text { An update search of all databases was conducted 29th January } \\
\text { 2007. No additional studies were identified. }\end{array}$ \\
\hline
\end{tabular}

\section{CONTRIBUTIONS OF AUTHORS}

Declan Millett (DTM), Anne-Marie Glenny (AMG) and Nicola Mandall (NAM) wrote the protocol with input from Rye Mattick (CRM) and Joy Hickman (JH). The review was written by DTM and AMG with input from NAM. DTM and AMG co-ordinated the review. AMG wrote letters to the authors. DTM, AMG, CRM, JH and NAM independently assessed the eligibility of the trials, extracted data and assessed the quality of the trials.

\section{DECLARATIONS OF INTEREST}

None known.

\section{SOURCES OF SUPPORT}

\section{Internal sources}

- Cork Dental School and Hospital, UK.

- University Dental Hospital of Manchester, UK.

- Newcastle Dental Hospital, UK.

- Glan Clwyd Hospital, North Wales, UK.

\section{External sources}

- National Institute for Health Research (NIHR), UK.

This project was supported by the NIHR, via Cochrane Infrastructure funding to Cochrane Oral Health. The views and opinions expressed therein are those of the review authors and do not necessarily reflect those of the Systematic Reviews Programme, the NIHR, the NHS or the Department of Health.

- Cochrane Oral Health Global Alliance, Other.

The production of Cochrane Oral Health reviews has been supported financially by our Global Alliance since 2011 (ohg.cochrane.org/ partnerships-alliances). Contributors over the last year have been: British Association for the Study of Community Dentistry, UK; British Society of Paediatric Dentistry, UK; Centre for Dental Education and Research at All India Institute of Medical Sciences, India; National Center for Dental Hygiene Research \& Practice, USA; New York University College of Dentistry, USA; NHS Education for Scotland, UK. 


\section{NOTES}

This review will not be updated until a substantial body of evidence on the topic becomes available. If trials are conducted and found eligible for inclusion in the future, the review would then be updated accordingly.

\section{INDEX TERMS}

\section{Medical Subject Headings (MeSH)}

${ }^{\star}$ Orthodontic Brackets; Adhesives [ ${ }^{*}$ standards]; Clinical Trials as Topic; Dental Bonding; Dental Caries [ ${ }^{*}$ prevention \& control]; Dental Cements [* ${ }^{\star}$ standards]; Glass lonomer Cements [standards]; Molar; Orthodontics [ ${ }^{\star}$ standards]; Resin Cements [standards]; Zinc Phosphate Cement [standards]

\section{MeSH check words}

Adolescent; Female; Humans; Male; Young Adult 